\title{
DESAIN SISTEM SMART ATTENDANCE MENGGUNAKAN KOMBINASI SMART CARD DAN SIDIK JARI
}

\author{
Ahmadi Yuli Ananta, Noprianto, Vivi Nur Wijayaningrum \\ Jurusan Teknologi Informasi, Politeknik Negeri Malang \\ Jalan Soekarno Hatta 9, Malang \\ Email:ahmadi@polinema.ac.id, noprianto@polinema.ac.id, vivinurw@polinema.ac.id
}

(Diterima: 21 Mei 2020 ,direvisi: 28 Juni 2020, disetujui: 25 Juli 2020)

\begin{abstract}
Monitoring student attendance during class hours required by each university due to the presence of the students proved to have a positive correlation with the performance of students during their studies. Most universities still use conventional techniques to record student attendance during teaching and learning in the classroom. Conventional techniques are inefficient and ineffective because they tend to spend a lot of time to record attendance and fraud appeared in the form of false presence. In this study a system that combines smart card and fingerprint technology is proposed to reduce fraud during the process of recording attendance in class, as well as making it easier for academics to manage attendance data. This system consists of card personalization applications, card reading applications, and attendance monitoring applications. The test results show that all three applications in this system give the expected results. In addition, the system is proven to be able to reduce frauds that occur in the classroom because there are two validation processes at the time of recording attendance namely smart card and fingerprint validation. With fingerprint validation, students cannot commit fraud because fingerprints are difficult to be manipulated or duplicated.
\end{abstract}

Keywords: attendance, fraud,identification, illegal attendance, near field communication

\begin{abstract}
ABSTRAK
Pemantauan kehadiran mahasiswa selama jam perkuliahan di kelas sangat perlu dilakukan oleh setiap perguruan tinggi karena kehadiran mahasiswa terbukti mempunyai korelasi positif terhadap kinerja mahasiswa tersebut selama masa studinya. Sebagian besar perguruan tinggi masih menggunakan teknik konvensional untuk mencatat kehadiran mahasiswa selama proses belajar mengajar di kelas. Teknik konvensional tersebut tidak efisien dan tidak efektif karena cenderung menghabiskan banyak waktu untuk pencatatan kehadiran dan muncul tindak kecurangan berupa kehadiran palsu. Penelitian ini mengusulkan sebuah sistem yang mengombinasikan teknologi smart card dan sidik jari untuk mengurangi tindakan kecurangan pada saat proses pencatatan kehadiran di kelas, serta memudahkan pihak akademik untuk mengelola data kehadiran. Sistem ini terdiri dari aplikasi personalisasi kartu, aplikasi pembacaan kartu, dan aplikasi monitoring kehadiran. Hasil pengujian menunjukkan bahwa ketiga aplikasi di dalam sistem ini memberikan hasil sesuai yang diharapkan. Selain itu, sistem terbukti dapat mengurangi tindakan kecurangan yang terjadi di dalam kelas karena adanya dua kali proses validasi pada saat pencatatan kehadiran yaitu validasi smart card dan sidik jari. Dengan adanya validasi sidik jari, mahasiswa tidak dapat melakukan titip absen karena sidik jari sulit untuk dimanipulasi atau diduplikasi.
\end{abstract}

Kata Kunci: kehadiran, kecurangan, identifikasi, titip absen, near field communication

\section{PENDAHULUAN}

Pencatatan kehadiran mahasiswa pada berbagai aktivitas di kampus, khususnya pada saat jam perkuliahan, merupakan hal yang sangat diperhatikan oleh setiap perguruan tinggi. Kehadiran mahasiswa selama perkuliahan dan kegiatan pembelajaran lainnya terbukti mempunyai korelasi positif terhadap kinerja mahasiswa tersebut selama masa studinya. Mahasiswa dengan tingkat kehadiran rendah cenderung berprestasi lebih rendah dibandingkan mahasiswa yang tingkat 
kehadirannya tinggi [1]-[4]. Oleh karena itu, kehadiran mahasiswa perlu dipantau oleh pihak kampus sebagai salah satu upaya untuk meningkatkan kinerja mahasiswa.

Beberapa perguruan tinggi menerapkan aturan mengenai persyaratan kelayakan mahasiswa untuk mengikuti ujian dengan memperhatikan total kehadiran mahasiswa tersebut di setiap mata kuliah. Mahasiswa di Universitas Islam Indonesia diperbolehkan mengikuti ujian dengan syarat minimal kehadirannya di kelas sebesar 75\% [5]. Aturan mengenai kedisiplinan mahasiswa selama jam perkuliahan sebagai syarat untuk mengikuti ujian semester juga diberlakukan di Universitas Muhammadiyah Purwokerto [6]. Berbeda dengan kedua perguruan tinggi tersebut, Politeknik Negeri Malang mempunyai aturan bahwa tingkat kehadiran mahasiswa akan mempengaruhi status mahasiswa. Mahasiswa dapat dinyatakan putus studi jika jumlah kumulatif ketidakhadirannya, baik karena sakit, izin, dan alpa, mencapai 152 jam atau lebih dalam satu tahun akademik. Dengan demikian, monitor terhadap kehadiran mahasiswa selama jam perkuliahan sangat diperlukan untuk menghindari adanya mahasiswa putus studi.

Saat ini pencatatan kehadiran mahasiswa selama jam perkuliahan masih cenderung dilakukan secara konvensional yaitu dengan cara memanggil nama mahasiswa satu persatu untuk dicatat oleh dosen pada formulir kehadiran. Dengan meningkatnya jumlah mahasiswa yang mengikuti kelas tersebut, tentu dapat menyebabkan tersitanya banyak waktu. Permasalahan ini dapat diatasi dengan cara memberikan formulir kehadiran kepada mahasiswa untuk ditandatangani pada saat jam perkuliahan sedang berlangsung. Namun, mekanisme ini juga mempunyai kelemahan yaitu memungkinkan mahasiswa untuk melakukan tindak kecurangan. Pada kasus ini, seorang mahasiswa bisa mengisikan tanda tangan atas nama mahasiswa lain yang saat itu tidak hadir di kelas. Hal ini disebabkan karena kurangnya kontrol terhadap formulir kehadiran, terlebih lagi jika mahasiswa yang terdapat pada kelas tersebut berjumlah cukup banyak. Mekanisme pencatatan kehadiran konvensional yang menggunakan formulir kehadiran terbukti memunculkan berbagai permasalahan seperti pemborosan waktu, kehadiran palsu, kesalahan peletakan formulir kehadiran, dan kesalahan pengisian data sehingga menjadikan mekanisme ini tidak akurat, tidak efisien, dan tidak efektif [7][8].

Permasalahan mengenai rekapitulasi data kehadiran ini tidak hanya terjadi pada sisi mahasiswa saja, namun pihak akademik juga mengalami kendala pada saat melakukan rekapitulasi data kehadiran mahasiswa secara manual. Hal ini dikarenakan seringnya terjadi kesalahan rekapitulasi data akibat human error. Tentunya hal ini menyebabkan diperlukannya sebuah inovasi untuk memberikan solusi terhadap berbagai kemungkinan yang terjadi pada saat proses rekapitulasi data, serta meningkatkan efektivitas dalam proses rekapitulasi data kehadiran.

Tujuan dari penelitian ini adalah untuk mengurangi tindakan kecurangan yang dapat dilakukan oleh mahasiswa dalam mengisikan data kehadiran pada saat jam perkuliahan di kelas dan memudahkan proses rekapitulasi data kehadiran mahasiswa yang dilakukan oleh pihak akademik dengan memanfaatkan teknologi smart card yang dikombinasikan dengan sidik jari. Dengan demikian, suasana belajar mengajar di kelas menjadi lebih kondusif.

\section{TINJAUAN PUSTAKA}

Rahni [9] membuat sebuah sistem pemantauan kehadiran mahasiswa Universiti Kebangsaan Malaysia secara online berbasis Quick Response (QR) Code dengan memanfaatkan perangkat seluler untuk menampilkan dan memindai $\mathrm{QR}$ Code. Interaksi yang dapat dilakukan oleh mahasiswa dengan sistem adalah melalui QR Code unik yang disediakan untuk setiap mahasiswa. QR Code yang dihasilkan untuk setiap mahasiswa dapat ditampilkan menggunakan smartphone atau dicetak jika mahasiswa tidak memiliki smartphone. Ketika mahasiswa hadir mengikuti jam perkuliahan, QR Code yang dimiliki mahasiswa akan dipindai oleh dosen menggunakan perangkat seluler seperti smartphone dan tablet. QR Code yang dipindai akan langsung terhubung dengan sistem SAMS ${ }^{\mathrm{TM}}$ berbasis web dan mencatat data kehadiran mahasiswa. Sistem ini dibuat untuk menghilangkan kebutuhan perangkat keras tambahan yang diperlukan dalam proses pemantauan kehadiran mahasiswa [9].

Pada beberapa penelitian selanjutnya, teknologi Radio Frequency Identification (RFID) banyak digunakan untuk menggantikan teknologi barcode konvensional. Hal ini dikarenakan teknologi RFID memungkinkan untuk melakukan identifikasi dari jarak jauh [10][11], pembacaan tag secara paralel [12], serta tidak memerlukan izin Line of Sight (LOS) seperti pada penggunaan teknologi barcode, 
termasuk QR Code [13]. Adeniran menggunakan RFID untuk membuat sistem pemantauan kehadiran otomatis di Universitas Ilorin, Nigeria [8]. Sistem pemantauan kehadiran ini membutuhkan koneksi antara program yang sudah dibuat dengan pembaca RFID yang saling berintegrasi. Koneksi dibuat menggunakan kabel USB atau kabel Ethernet sehingga memungkinkan pembaca RFID dan program saling bertukar informasi dalam bentuk perintah. Pembaca RFID akan membaca Unique Identifier (UID) pada tag dan mengirimkan data tersebut ke program untuk diproses. Sistem yang terhubung dengan pembaca RFID terhubung dengan database, sehingga secara otomatis dapat menyimpan kehadiran mahasiswa dan menghitung persentase kehadiran mahasiswa berdasarkan permintaan yang dilakukan. Pada penelitian lainnya, penggunaan RFID untuk memonitor kehadiran mahasiswa pada kegiatan di universitas juga dilakukan oleh Gining [14].

Meskipun teknologi RFID banyak digunakan karena mempunyai beberapa keunggulan dibandingkan teknologi barcode, nyatanya RFID juga mempunya beberapa kelemahan, antara lain adalah gelombang radio yang digunakan untuk media komunikasi RFID dapat diblokir oleh material logam dan cairan sehingga informasi tidak akan dikirimkan dengan benar, serta terdapat kekhawatiran pada privasi pengguna karena tag RFID dapat dibaca oleh siapa pun dengan menggunakan pembaca RFID [15]. Oleh karena itu, sistem biometrika saat ini sedang diadopsi secara luas sebagai pendekatan yang aman untuk pengembangan sistem manajemen kehadiran. Teknologi pengenalan wajah adalah salah satu fitur yang digunakan untuk memonitor kehadiran dengan cara menganalisis tampilan dari wajah seseorang yang diperoleh melalui kamera [16]. Teknologi ini mengukur seluruh struktur wajah seseorang, seperti jarak antar mata, mulut, hidung, dan tepi rahang dengan tolak ukur yang diambil dari database [17]. Namun, kelemahan dari teknologi ini adalah intensitas cahaya dan pose kepala dapat menyebabkan sulitnya pengenalan wajah yang menyebabkan wajah tersebut tidak terdeteksi dan tidak dapat dikenali [18].

Pada penelitian sebelumnya, sebuah sistem untuk memonitor kehadiran mahasiswa dan dosen dibangun menggunakan Near Field Communication (NFC) [19]. Proses identifikasi mahasiswa dan dosen selama kegiatan belajar mengajar di kelas dilakukan dengan memanfaatkan smart card yang dimiliki oleh masing-masing mahasiswa dan dosen. Setiap smart card mempunyai nomor seri yang akan dibaca oleh pembaca NFC. Ketika mahasiswa atau dosen menempelkan smart card ke pembaca NFC, maka nomor seri akan dikirimkan ke server untuk diverifikasi ada atau tidaknya data dengan nomor seri tersebut di dalam database. Teknologi yang digunakan dalam NFC ini didasarkan pada ide RFID yang menggunakan induksi elektromagnetik untuk mentransfer informasi. Sistem NFC memberikan lebih banyak kemudahan dan infrastruktur yang lebih murah baik dalam biaya operasional maupun pengaturan [20]. Namun, proses pencatatan kehadiran dengan hanya memanfaatkan smart card memungkinkan terjadinya kecurangan yaitu seorang mahasiswa dapat menempelkan smart card milik mahasiswa lain yang tidak hadir di kelas sehingga mahasiswa yang tidak hadir tersebut tercatat hadir.

Pada penelitian ini diusulkan desain sistem untuk monitor kehadiran mahasiswa dan dosen menggunakan kombinasi smart card dan sidik jari. Dengan adanya tambahan sidik jari, diharapkan tidak ada kecurangan yang terjadi karena sistem akan melakukan verifikasi identitas sebanyak dua kali melalui data mahasiswa ataupun dosen di dalam smart card dan sidik jari yang dipindai oleh pengguna yang membawa smart card tersebut.

\subsection{Smart Card}

Smart card merupakan sebuah perangkat portabel yang mempunyai kemampuan untuk menghitung, menyimpan, dan memuat data di dalam sebuah chip prosesor tertanam untuk proses verifikasi identitas pribadi [21]. Hal ini menandakan bahwa smart card dapat menerima masukan yang kemudian diproses melalui aplikasi Integrated Circuit Card (ICC) dan dikirimkan sebagai keluaran [22]. Smart card ini digunakan bersama dengan card reader yang dimaksudkan untuk menerima data dari chip kartu, menganalisis, dan merespons data. Smart card banyak digunakan sebagai kartu identifikasi pribadi karena smart card mampu memberikan portabilitas, kenyamanan, dan keamanan data [23].

Pada penelitian ini, jenis smart card yang digunakan adalah contactless card. Hal ini dikarenakan contactless card lebih efisien dan menghemat waktu. Pada contactless card, chip yang tertanam berisi 
antena kecil, dan sinyal frekuensi radio yang digunakan untuk komunikasi antara kartu dan reader. Dengan demikian, tidak diperlukan adanya kontak fisik antar keduanya [23].

\subsection{Near Field Communication}

Near Field Communication (NFC) adalah standar komunikasi nirkabel yang memungkinkan dua perangkat dalam jarak pendek untuk membangun saluran komunikasi dalam waktu singkat melalui gelombang radio dalam rentang frekuensi $13.56 \mathrm{MHz}$. NFC dapat menjadi teknologi yang berguna untuk transfer data antara dua perangkat yang berdekatan satu sama lain. Teknologi NFC ini lebih aman dari teknologi nirkabel lainnya seperti Bluetooth dan Wi-Fi karena pada NFC kedua kedua perangkat berada berdekatan satu sama lain (kurang dari $10 \mathrm{~cm}$ ) [24].

\section{METODE PENELITIAN}

Beberapa tahapan yang dilakukan pada penelitian ini adalah studi literatur, perancangan sistem, implementasi sistem, pengujian sistem, dan analisis hasil pengujian sistem. Penelitian ini diawali dengan mempelajari beberapa referensi penelitian yang berkaitan dengan rekapitulasi kehadiran dengan menggunakan berbagai teknologi. Berdasarkan referensi penelitian yang sudah ada, didapatkan kelebihan dan kekurangan setiap teknologi yang sudah diterapkan untuk sistem pencatatan kehadiran. Dengan demikian, pada penelitian ini diusulkan teknologi lain untuk mengatasi kelemahan dari sistem pencatatan kehadiran yang sudah dibuat oleh peneliti lain. Untuk menguji performa dari sistem yang dibuat pada penelitian ini, dilakukan pengujian dan analisis hasil pengujian agar dapat diketahui seberapa baik sistem yang diusulkan, sehingga dapat disimpulkan keberhasilan sistem dalam mengatasi permasalahan rekapitulasi kehadiran mahasiswa.

Teknologi yang diterapkan pada penelitian ini adalah kombinasi smart card dan sidik jari untuk perekaman kehadiran mahasiswa di kelas. Perangkat keras yang dibutuhkan dalam penelitian ini antara lain CPU 2,5 GHz Intel Core i5, memori DDR3 8 GB, Intel HD Graphics 40001536 MB, sistem operasi MacOS Mojave, dan media penyimpanan SSD 250 GB. Kemudian perangkat lunak yang dipergunakan adalah Java 8, Python 3, Visual Studio Code, dan NetBeans 8.2.

\section{HASIL DAN PEMBAHASAN}

Pada penelitian ini, beberapa data yang digunakan meliputi data mahasiswa dan dosen yang menggunakan kelas-kelas tertentu sesuai jadwal perkuliahan. Data ini diperoleh dari UPT. PUSKOM Politeknik Negeri Malang. Nantinya data tersebut disimpan di dalam smart card agar proses pengecekan data dapat dilakukan secara offline sehingga proses transaksi yang dilakukan menjadi lebih cepat. Tabel 1 menunjukkan struktur data yang akan disimpan di dalam smart card.

Tabel 1. Struktur Data Smart Card

\begin{tabular}{llcll}
\hline No & \multicolumn{1}{c}{ Field } & $\begin{array}{c}\text { Panjang } \\
(\text { byte })\end{array}$ & Format & \multicolumn{1}{c}{ Kegunaan } \\
\hline 1 & TNKB & 10 & ASCII & $\begin{array}{l}\text { Menyimpan Tanda Nomor Kendaraan } \\
\text { Bermotor (TNKB) }\end{array}$ \\
\hline 2 & Tanggal transaksi & 4 & Hexadesimal & Menyimpan tanggal transaksi \\
\hline 3 & Status masuk & 1 & Numerik & Menyimpan status masuk \\
\hline 4 & Kode gate & 1 & Numerik & Menyimpan informasi kode gate \\
\hline 5 & NIP atau NIM & 18 & ASCII & $\begin{array}{l}\text { Menyimpan Nomor Induk Pegawai (NIP) } \\
\text { untuk pengguna dosen atau Nomor Induk } \\
\text { Mahasiswa untuk pengguna mahasiswa }\end{array}$ \\
\hline 6 & Kedaluwarsa kartu & 4 & Hexadesimal & Menyimpan tanggal kedaluwarsa kartu \\
\hline 7 & Status kartu & 1 & Numerik & Menyimpan status kartu (aktif atau pasif) \\
\hline
\end{tabular}

Pada Tabel 1, terlihat bahwa smart card juga diisi dengan data TNKB yang dimiliki oleh pengguna, hal ini dimaksudkan bahwa selain digunakan untuk pencatatan kehadiran, smart card juga nantinya dapat digunakan untuk sistem parkir kendaraan bermotor di lingkungan kampus. Untuk 
melakukan identifikasi pengguna, NIP dosen atau NIM mahasiswa dan template sidik jari yang tersimpan akan dicocokkan dengan data yang ada di dalam database.

\subsection{Arsitektur Sistem}

Untuk membangun sistem smart attendance, beberapa perangkat yang digunakan terdiri dari Raspberry Pi 4 Model B, LCD 20×4, NFC Reader PN532, module fingerprint, dan smart card. Arsitektur sistem yang melibatkan perangkat-perangkat tersebut ditunjukkan pada Gambar 1.

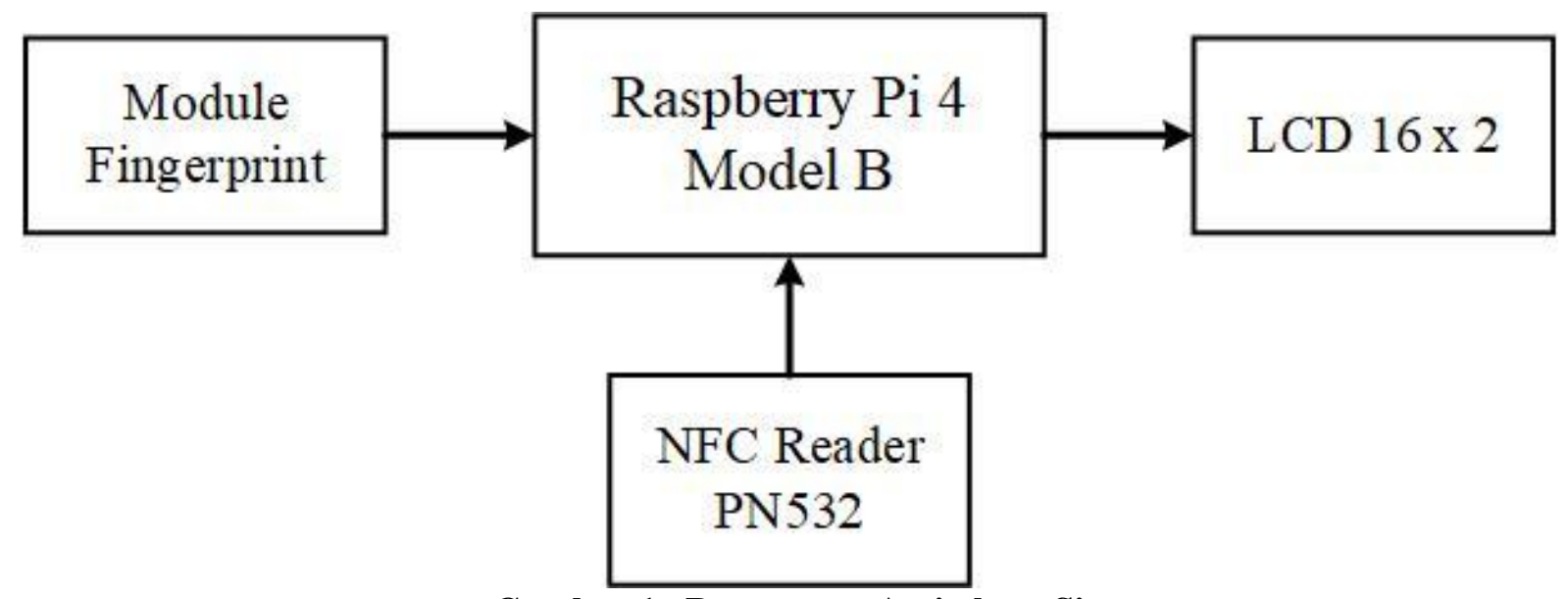

Gambar 1. Rancangan Arsitektur Sistem

Deskripsi singkat mengenai fungsi perangkat yang digunakan adalah sebagai berikut:

a. Raspberry Pi 4 Model B digunakan untuk menginstalasi aplikasi atau sebagai controller dari semua perangkat

b. LCD 20×4 digunakan untuk menampilkan status transaksi dan informasi lainnya

c. NFC Reader PN532 digunakan untuk operasi baca / tulis pada smart card

d. Module fingerprint digunakan untuk memindai sidik jari dari mahasiswa dan dosen

e. Smart card digunakan untuk menyimpan informasi mahasiswa dan dosen seperti yang ditunjukkan pada Tabel 1.

\subsection{Verifikasi Identitas Pengguna}

Verifikasi identitas pengguna pada sistem dilakukan sebanyak dua kali. Autentikasi pertama untuk mengecek valid atau tidaknya data pengguna pada smart card dan autentikasi kedua untuk mengecek kesesuaian sidik jari yang dipindai dengan template sidik jari yang tersimpan di database. Jika autentikasi pertama gagal, maka langkah autentikasi berikutnya tidak akan pernah dijalankan dan sistem akan berhenti. Verifikasi identitas pengguna pada sistem ditunjukkan pada Gambar 2.

Alur verifikasi identitas pengguna seperti pada Gambar 2 diawali dengan inisialisasi sistem. Inisialisasi sistem digunakan untuk mempersiapkan sistem sehingga sistem siap menerima data masukan dari pengguna. Pengguna yang terdiri dari mahasiswa dan dosen menempelkan smart card yang dimilikinya ke reader untuk pengecekan valid atau tidaknya data pengguna pada smart card tersebut. Proses ini dilakukan dengan mengecek nomor seri yang terdapat pada smart card. Apabila nomor seri tidak valid, artinya smart card tersebut tidak terdaftar pada sistem sehingga tidak dikenali oleh sistem, sehingga sistem akan menampilkan pesan error dan pengguna diminta menempelkan smart card kembali menggunakan kartu yang sesuai dengan nomor seri dari smart card dianggap valid. Apabila pengecekan nomor seri valid, maka selanjutnya sistem meminta pengguna untuk memindai sidik jarinya. Kemudian sistem akan mengecek kesesuaian sidik jari yang dipindai tersebut dengan template sidik jari yang tersimpan di dalam database sesuai dengan data pengguna tersebut. Apabila sidik jari tidak sesuai, maka sistem akan menampilkan pesan dan meminta pengguna untuk mengulangi proses menempelkan smart card ke reader. Sedangkan apabila sidik jari tersebut sesuai, maka sistem akan melakukan request ke endpoint (web service) UPT. PUSKOM Politeknik Negeri Malang dan kemudian menampilkan informasi kehadiran dari pengguna tersebut. 


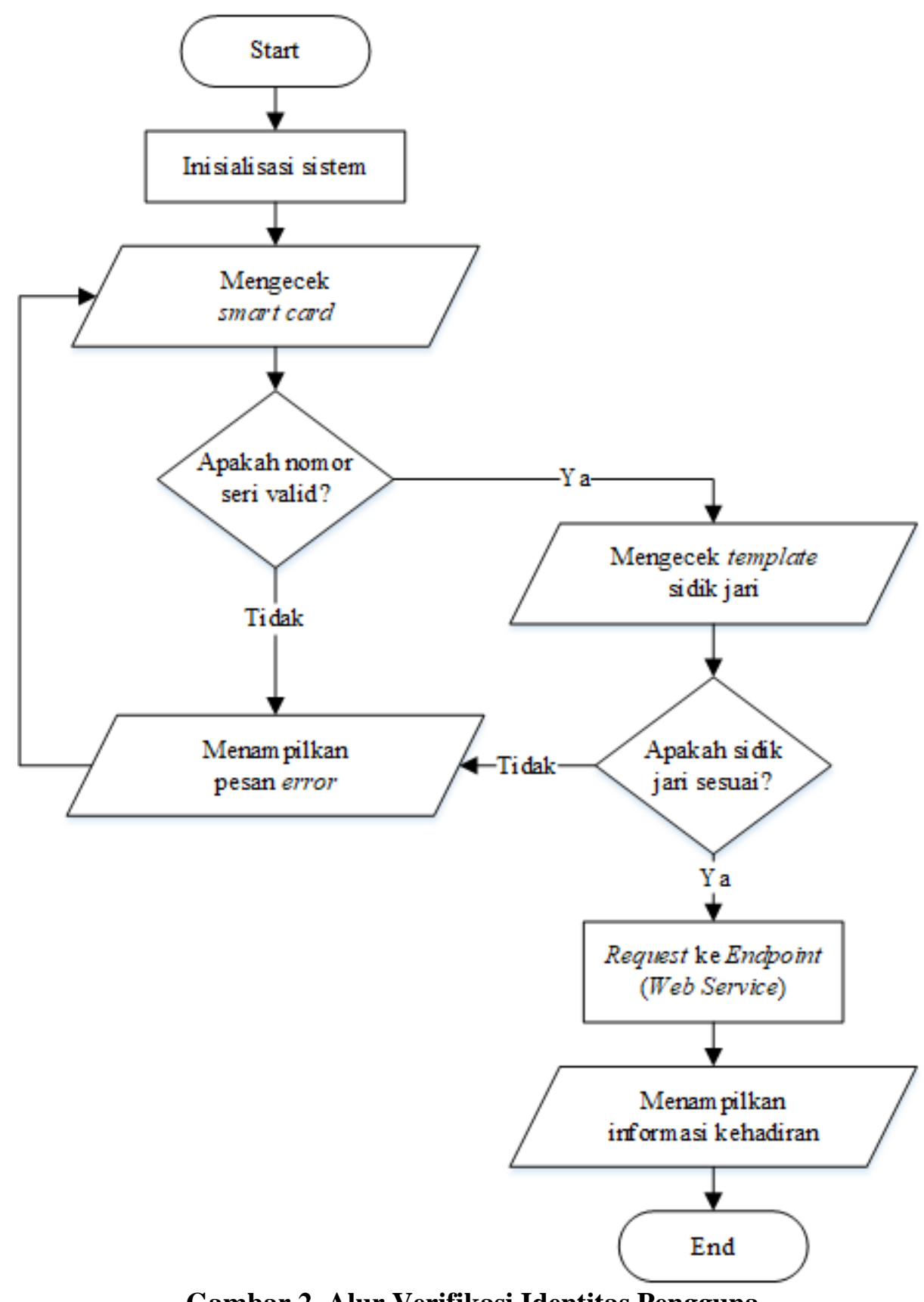

\section{Gambar 2. Alur Verifikasi Identitas Pengguna}

Langkah awal yang dilakukan sebelum menggunakan sistem smart attendance ini adalah proses pendaftaran kartu. Proses pendaftaran (personalisasi) kartu digunakan untuk melakukan pairing antara kartu dengan pemegang kartu (pengguna). Proses personalisasi kartu dilakukan dengan menggunakan aplikasi berbasis desktop dengan menghubungkannya ke sebuah web service REST API agar dapat memisahkan layer aplikasi dengan layer database. Selanjutnya, proses pairing ini disimpan pada Sistem Akademik (SIAKAD) yang dikelola oleh UPT. PUSKOM Politeknik Negeri Malang untuk kepentingan validasi data pemegang kartu ketika melakukan proses pencatatan kehadiran. Desain antarmuka aplikasi personalisasi kartu ditunjukkan pada Gambar 3. 


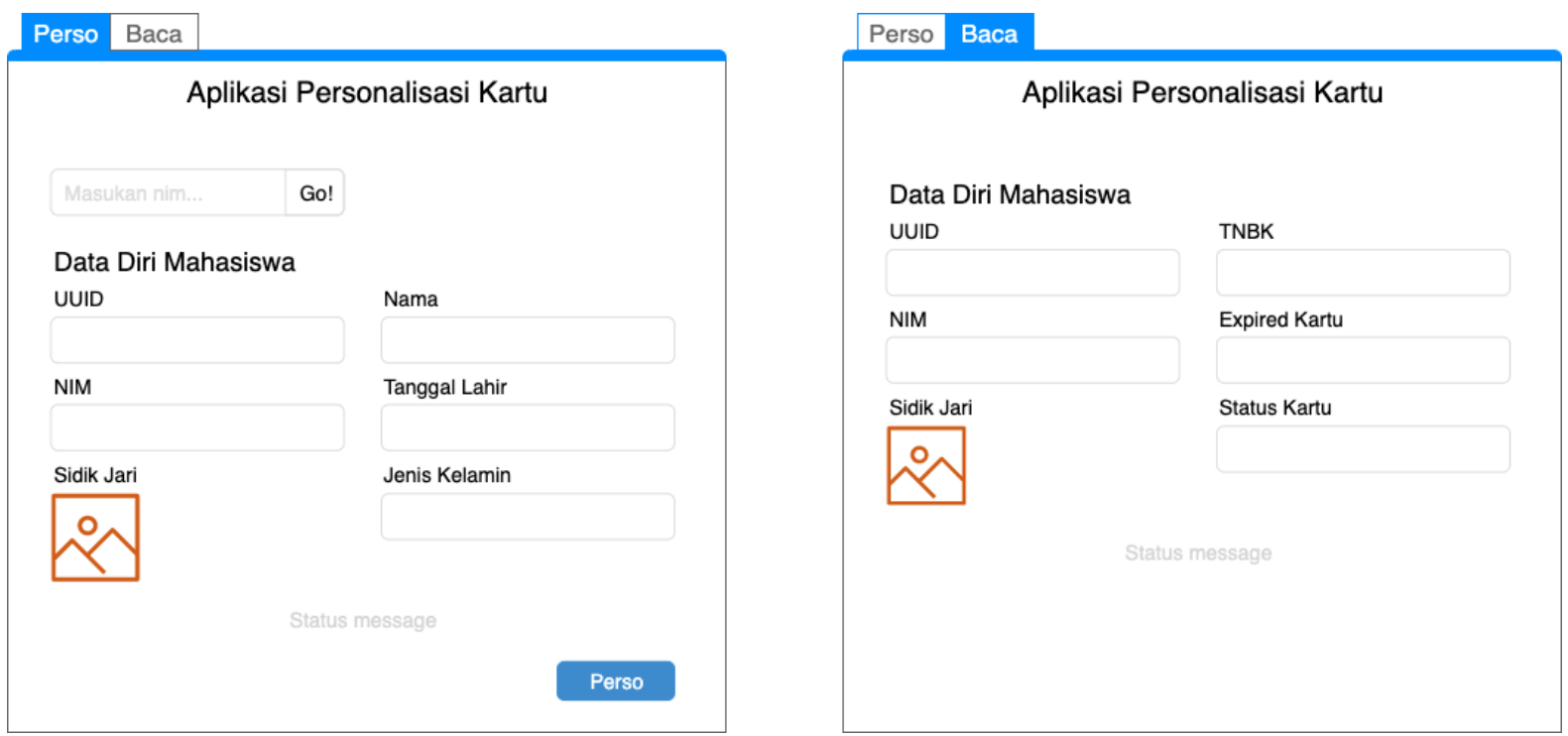

Gambar 3. Desain Antarmuka Aplikasi Personalisasi Kartu

Pada Gambar 3, terdapat dua tab yang terdiri dari tab Perso dan tab Baca. Tab Perso atau Personalisasi digunakan untuk menuliskan data mahasiswa atau dosen ke dalam kartu sesuai dengan identitas masing-masing pemegang kartu. Langkah pertama yang dilakukan adalah memasukkan NIM untuk mencari data mahasiswa. Pada proses ini, sistem akan melakukan request ke endpoint (web service) yang disediakan oleh UPT. PUSKOM. Apabila data mahasiwa ditemukan, maka pengguna perlu menempelkan kartu baru pada sebuah reader smart card dan sidik jari pada sebuah reader sidak jari. Selanjutnya, langkah terakhir yang perlu dilakukan adalah melakukan Perso atau personalisasi. Ketika melakukan Perso, data personalisasi yang sudah diisikan sebelumnya akan dikirimkan melalui web service untuk dilakukan penyimpanan ke database.

Tab Baca pada Gambar 3 digunakan untuk membaca data kartu hasil personalisasi. Proses pembacaan ini dilakukan secara offline, yaitu hanya berupa komunikasi antara reader dengan smart card. Hal ini merupakan salah satu keunggulan smart card dalam bertransaksi karena proses transaksi menjadi lebih cepat saat melakukan pencatatan kehadiran. Pada halaman tersebut juga terdapat informasi mengenai expired kartu yang dapat dimanfaatkan untuk membatasi penggunaan kartu dalam rentang waktu tertentu. Misalkan kartu hanya diatur dapat aktif selama satu semester, maka setelah satu semester penggunaan, kartu tersebut tidak dapat digunakan kembali sebelum masa aktif kartu diperpanjang. Proses memperpanjang masa aktif kartu dapat dilakukan setelah mahasiswa pemegang kartu melakukan pelunasan pembiayaan akademik, biaya praktikum, dan Uang Kuliah Tunggal (UKT). Sedangkan kartu yang dimiliki oleh dosen akan secara otomatis diperpanjang setiap akhir semester setelah kegiatan akademik dalam satu semester telah selesai.

Setelah kartu yang dimiliki oleh pengguna didaftarkan dan data personalisasinya disimpan pada SIAKAD, selanjutnya kartu tersebut dapat digunakan pada sistem smart attendance. Proses komunikasi dilakukan oleh sistem smart attendance ini dengan SIAKAD yang menggunakan API endpoint (web service) yang disediakan oleh UPT. PUSKOM Politeknik Negeri Malang dengan memanfaatkan access point pada setiap ruangan di jaringan lokal Politeknik Negeri Malang. Gambaran dari alur sistem smart attendance yang akan dibuat ditunjukkan pada Gambar 4. 

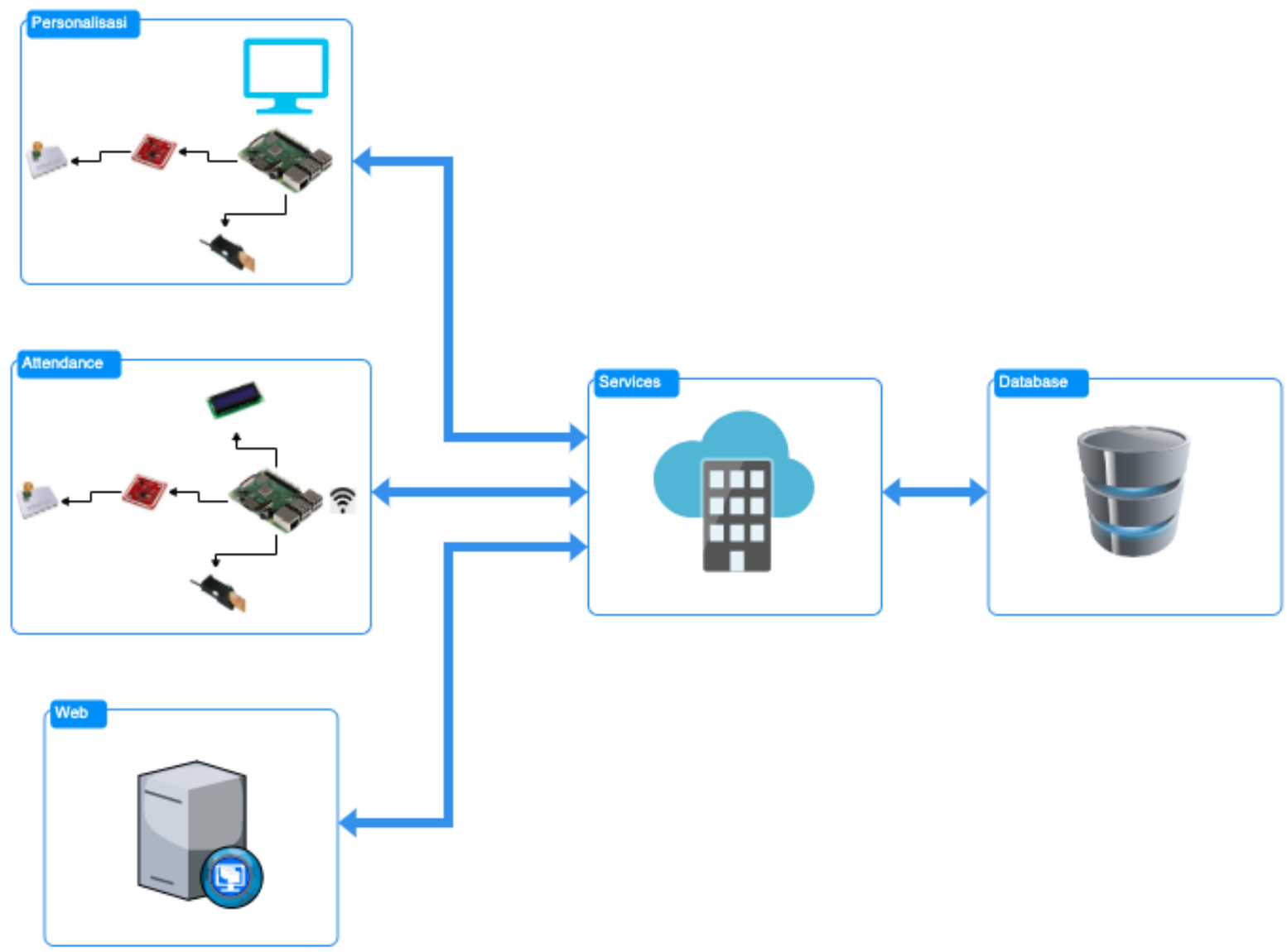

Gambar 4. Alur Sistem Smart Attendance

Pada Gambar 4, diketahui bahwa sistem smart attendance dan SIAKAD Politeknik Negeri Malang saling berhubungan untuk bertukar informasi. Segala bentuk data yang diperlukan untuk pencatatan kehadiran mahasiswa dan dosen selama jam perkuliahan disimpan pada database SIAKAD, yang terdiri dari ruangan yang digunakan, daftar nama mahasiswa setiap kelas, jadwal kuliah, nama dosen pengampu, dan data lainnya yang berkaitan dengan kegiatan akademik. Sistem smart attendance ini akan mengecek kesesuaian data yang tersimpan di database SIAKAD setiap kali pengguna menempelkan kartu ke reader dan memindai sidik jari. Apabila proses berhasil dan data pengguna sesuai dengan data di database, maka pengguna tersebut akan dicatat dengan status hadir pada mata kuliah tersebut sesuai dengan jadwal perkuliahan yang telah ditentukan, kemudian data kehadiran tersebut disimpan ke dalam SIAKAD. Pada Gambar 4 juga terdapat aplikasi web yang digunakan untuk memantau hasil pencatatan kehadiran mahasiswa yang dilakukan pada aplikasi pembaca kartu atau aplikasi yang berjalan pada perangkat Raspberry Pi. Sama halnya dengan aplikasi personalisasi kartu, aplikasi web berkomunikasi dengan database melalui web service REST API.

\subsection{Implementasi Sistem}

Secara garis besar, sistem pencatatan kehadiran mahasiswa yang diusulkan pada penelitian ini terdiri dari tiga aplikasi utama, yaitu aplikasi personalisasi kartu, aplikasi pembacaan kartu, dan aplikasi monitoring kehadiran.

\subsubsection{Aplikasi Personalisasi Kartu}

Aplikasi personalisasi kartu berfungsi untuk mendaftarkan smart card agar dapat digunakan ketika proses pencatatan kehadiran. Tujuan dari proses ini adalah agar data pemegang kartu, baik mahasiswa ataupun dosen cocok dengan data smart card. Tampilan pada aplikasi tersebut ditunjukkan pada Gambar 5. 


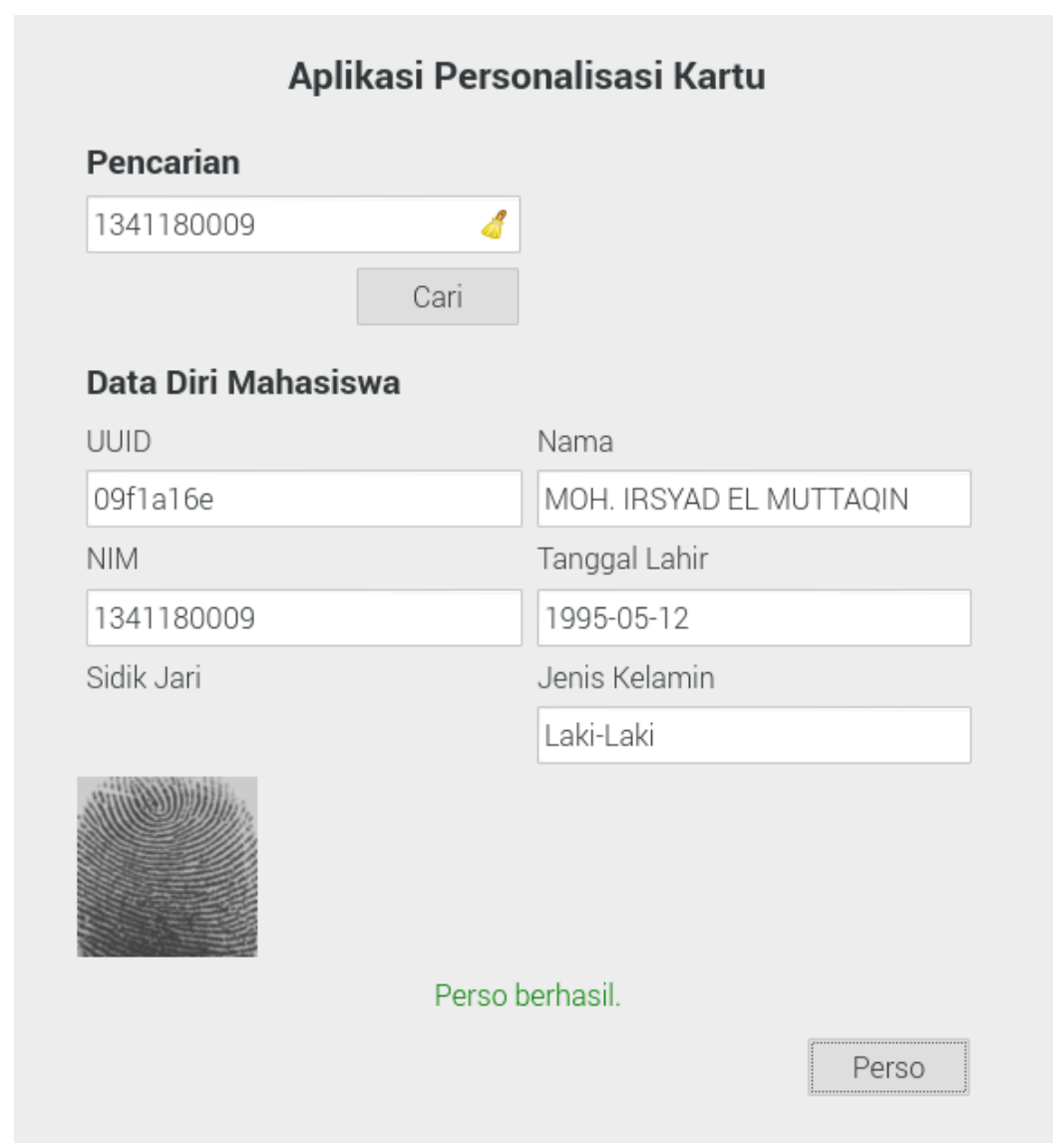

\section{Gambar 5. Personalisasi Kartu}

Proses personalisasi kartu adalah memasukan data sesuai dengan mapping pada Tabel 1 ke dalam sebuah smart card. Pada Gambar 5, terdapat tombol Cari yang berfungsi untuk mengambil data mahasiswa menggunakan REST API pada database yang terdapat di UPT. PUSKOM. Ketika data berhasil ditemukan, pengguna mahasiswa atau dosen diharuskan untuk meletakkan sidik jari pada finger scan untuk dilakukan perekaman template. Setelah data yang dibutuhkan lengkap, proses penyimpanan data akan dilakukan setelah pengguna menekan tombol Perso.

Data yang dituliskan di dalam smart card dialokasikan pada sebuah sector dan block. Sector dan block merupakan pengalamatan penyimpanan pada smart card. Sector dianalogikan sebagai nomor lantai pada sebuah hotel, sedangkan block diibaratkan sebagai nomor kamar pada sebuah hotel. Sebuah sector terdiri dari 4 block, sedangkan 1 block dapat menyimpan data sebesar 16 byte. Konsep seperti ini merupakan jenis smart card based on memory, artinya smart card tidak dapat diinstalasi Applet, tetapi hanya berfungsi sebagai penyimpanan data.

Sebelum menuliskan data pada smart card, hal yang pertama dilakukan adalah proses autentikasi pada sebuah sector yang akan dibaca. Autentikasi adalah proses memasukan enam byte key pada sebuah smart card, yang terdiri dari key $A$ dan key $B$. Fungsi dari key $A$ dan key $B$ adalah untuk mengatur akses smart card. Misalkan key $A$ hanya digunakan untuk membaca data, sedangkan key $B$ digunakan untuk membaca dan menuliskan data.

\subsubsection{Aplikasi Pembacaan Kartu}

Aplikasi pembacaan kartu diinstalasi pada sebuah device yang terdapat di dalam ruang kelas, yang bertujuan untuk melakukan pencatatan kehadiran mahasiswa dan dosen. Prototype aplikasi pembacaan kartu ditunjukkan pada Gambar 6. 


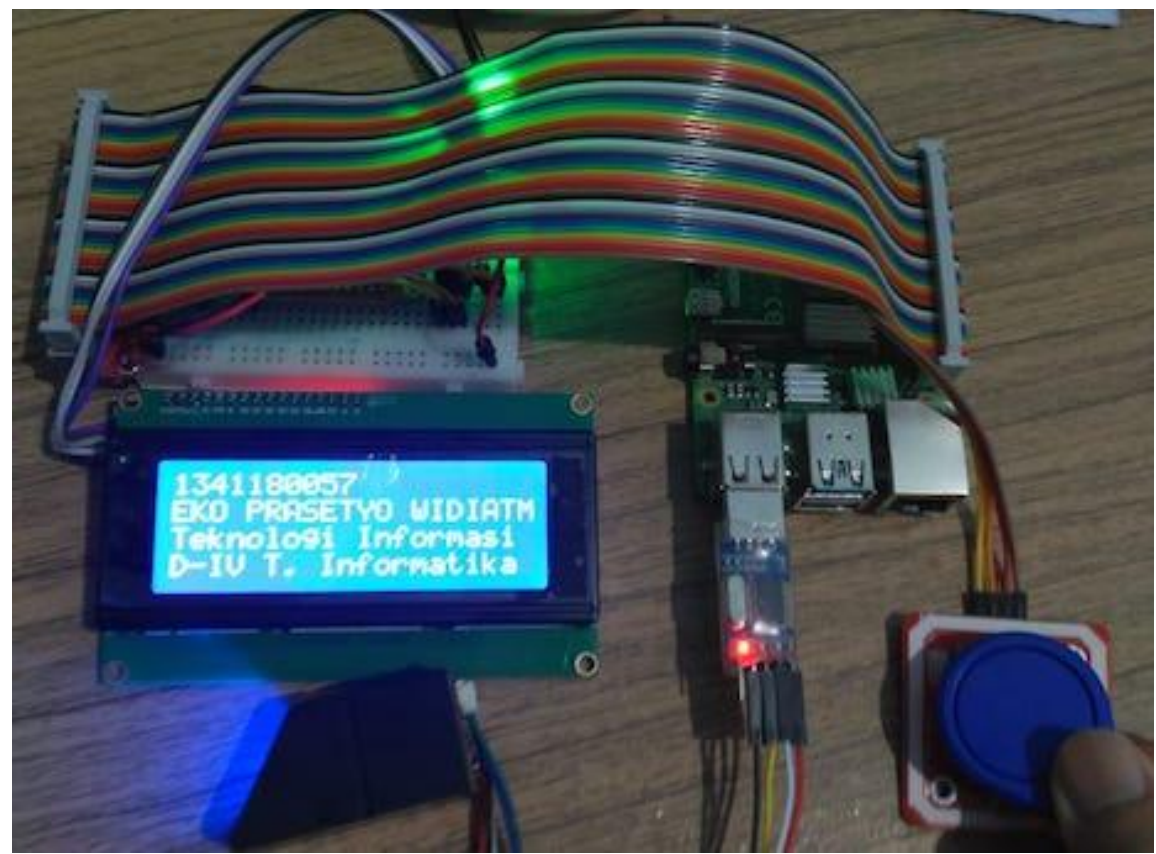

Gambar 6. Aplikasi Pembacaan Kartu

Prototype yang ditunjukkan pada Gambar 6 adalah proses penempelan smart card pada reader PN532 dan dilanjutkan dengan perekaman sidik jari pada finger scan. Setelah melakukan penempelan smart card dan perekaman sidik jari, data pengguna mahasiswa atau dosen akan ditampilkan pada LCD.

\subsubsection{Aplikasi Monitoring Kehadiran}

Untuk menampilkan data yang telah masuk, dibutuhkan sebuah aplikasi web monitoring atau rekapitulasi dari data yang berhasil direkam. Selain itu, aplikasi monitoring kehadiran juga berfungsi untuk menampilkan data hasil personalisasi smart card. Tampilan dari aplikasi monitoring kehadiran ditunjukkan pada Gambar 7.

\begin{tabular}{|c|c|c|c|c|c|c|}
\hline Aplikasi Presensi & Search & & & & & Sign out \\
\hline \multirow{11}{*}{$\begin{array}{l}\text { Dashboard } \\
\text { Mahasiswa } \\
\text { Personalisasi } \\
\text { Kehadiran }\end{array}$} & \multicolumn{6}{|l|}{ Rekap Presensi } \\
\hline & Id & NIM & Nama & Tanggal & Tanggal Masuk & \\
\hline & Oe $3724+3-e 17 d-48 d 7-b 531-1 b 1 d f c 4 e a b 42$ & 1341180009 & MOH. IRSYAD EL MUTTAQIN & $26-03-2020$ & 27-03-2020 06:55:53 & \\
\hline & $4682607 f-85 b 5-4 a 28-9362-2 e 816736757 b$ & 198911082019031020 & Noprianto & $11-02-2020$ & $11-02-2020$ 15:03:36 & \\
\hline & 6a84e 48f-8881-4d04-8b5d-f03668e70b55 & 1341180009 & MOH. IRSYAD EL MUTTAQIN & $23-03-2020$ & $24-03-202000: 26: 38$ & \\
\hline & $6 f 4 e 43 c f-1042-4 d d 3-90 e e-2 f 8 b 5 e 6 e d 1 b 4$ & 1341180057 & EKO PRASETYO WIDIATMOKO & 27-03-2020 & 27-03-2020 07:18:26 & \\
\hline & $746+0 \mathrm{~d} 23-5126-4 \mathrm{feb}-90 \mathrm{co}-4 \mathrm{a} 7831 \mathrm{coe} 4 \mathrm{df}$ & 1341180057 & EKO PRASETYO WIDIATMOKO & $27-03-2020$ & 27-03-2020 07:20:27 & \\
\hline & $83 b 3 b 689-5 c e b-46 d 0-85 e 0-10 c c d d 6 d 5 d 0 b$ & 1341180057 & EKO PRASETYO WIDIATMOKO & 27-03-2020 & 27-03-2020 07:21:13 & \\
\hline & 97c03838-aа2f-4cbe-b585-e82c1a44b39a & 1341180057 & EKO PRASETYO WIDIATMOKO & $27-03-2020$ & 27-03-2020 07:19:51 & \\
\hline & dc2f152b-1d15-454b-8ba2-at2fe9468663 & 1341180009 & MOH. IRSYAD EL MUTTAQIN & 23-03-2020 & 24-03-2020 00:24:15 & \\
\hline & Showing 1 to 8 of 8 entries & & « $, 1, \ldots$ & & & \\
\hline
\end{tabular}

Gambar 7. Rekapitulasi Kehadiran

Pada Gambar 7, ditunjukkan bahwa mahasiswa yang bernama EKO PRASETYO WIDIATOMO berhasil melakukan pencatatan kehadiran beberapa kali. Meskipun mahasiswa tersebut melakukan beberapa kali pencatatan kehadiran, sistem hanya menganggap satu data yang valid. Tujuan dari pencatatan kehadiran pengguna ketika dilakukan beberapa kali percobaan adalah untuk mengetahui tingkah laku dari masing-masing pemegang kartu.

\subsection{Pengujian Sistem}

Pengujian sistem pada penelitian ini dilakukan dengan menggunakan pengujian black box. Pengujian black box sering dikenal dengan sebutan pengujian fungsional, yaitu sebuah pengujian perangkat lunak yang dilakukan tanpa mengetahui struktur internal kode atau program. Hasil pengujian black box dari sistem pencatatan kehadiran pada penelitian ini dijabarkan pada Tabel 2. 
Tabel 2. Pengujian Proses Personalisasi

\begin{tabular}{|c|c|c|c|}
\hline Fungsi & Skenario & Hasil yang diharapkan & Status \\
\hline \multirow{2}{*}{ Pencarian data } & Memasukan NIM yang tersedia & $\begin{array}{l}\text { Data berhasil ditemukan dan dapat } \\
\text { melakukan Perso }\end{array}$ & Sesuai \\
\hline & $\begin{array}{l}\text { Memasukan NIM yang tidak } \\
\text { tersedia }\end{array}$ & $\begin{array}{l}\text { Data tidak ditemukan dan tidak } \\
\text { dapat melakukan Perso }\end{array}$ & Sesuai \\
\hline \multirow[t]{2}{*}{ Perso } & $\begin{array}{l}\text { Data sudah tersedia dari hasil } \\
\text { pencarian, menekan tombol } \\
\text { Perso, menempelkan smart } \\
\text { card, dan scan sidik jari } \\
\end{array}$ & $\begin{array}{l}\text { Menampilkan pesan yang } \\
\text { menyatakan berhasil Perso dan } \\
\text { data ditampilkan pada web } \\
\text { Monitoring }\end{array}$ & Sesuai \\
\hline & $\begin{array}{l}\text { Data belum dicari dan menekan } \\
\text { tombol Perso }\end{array}$ & $\begin{array}{l}\text { Menampilkan pesan bahwa data } \\
\text { tidak boleh kosong }\end{array}$ & Sesuai \\
\hline
\end{tabular}

Tabel 2 menunjukkan hasil pengujian aplikasi personalisasi dari proses pencarian data sampai dengan proses personalisasi, baik dengan skenario yang normal ataupun tidak normal. Selanjutnya, hasil pengujian pembacaan smart card ditunjukkan pada Tabel 3.

Tabel 3. Pembacaan Smart Card

\begin{tabular}{llll}
\hline \multicolumn{1}{c}{ Fungsi } & \multicolumn{1}{c}{ Skenario } & Hasil yang diharapkan & Status \\
\hline $\begin{array}{l}\text { Perekaman } \\
\text { kehadiran secara } \\
\text { normal }\end{array}$ & $\begin{array}{l}\text { Smart card ditempelkan pada reader, } \\
\text { dilanjutkan dengan scan sidik jari }\end{array}$ & $\begin{array}{l}\text { Akan muncul data } \\
\text { pemegang kartu pada LCD }\end{array}$ & Sesuai \\
\hline \multirow{2}{*}{$\begin{array}{l}\text { Perekaman } \\
\text { kehadiran secara } \\
\text { tidak normal }\end{array}$} & $\begin{array}{l}\text { Smart card ditempelkan pada reader } \\
\text { kartu yang berbeda }\end{array}$ & $\begin{array}{l}\text { Muncul pesan data } \\
\text { ditemukan pada LCD }\end{array}$ & Sesuai \\
\cline { 2 - 5 } & $\begin{array}{l}\text { Smart card ditempelkan pada reader, } \\
\text { dilanjutkan scan sidik jari dengan jari } \\
\text { yang berbeda ketika pendaftaran }\end{array}$ & $\begin{array}{l}\text { Menampilkan pesan sidik } \\
\text { jadi tidak cocok }\end{array}$ & Sesuai \\
\hline
\end{tabular}

Tabel 3 memperlihatkan bahwa pengujian aplikasi pembacaan smart card pada Raspberry dilakukan dengan perekaman kehadiran secara normal dan tidak normal memberikan hasil pengujian sesuai yang diharapkan. Selanjutnya, pada Tabel 4 ditunjukkan hasil pengujian aplikasi web monitoring.

Tabel 4. Pengujian Aplikasi Web Monitoring

\begin{tabular}{cllc}
\hline \multicolumn{1}{c}{ Fungsi } & \multicolumn{1}{c}{ Skenario } & \multicolumn{1}{c}{ Hasil yang diharapkan } & Status \\
\hline Data kehadiran & $\begin{array}{l}\text { Menempelkan smart card pada } \\
\text { reader beberapa kali }\end{array}$ & $\begin{array}{l}\text { Menampilkan data kehadiran } \\
\text { sebanyak penempelan smart card } \\
\text { pada reader }\end{array}$ & Sesuai \\
\hline $\begin{array}{l}\text { Data } \\
\text { personalisasi }\end{array}$ & $\begin{array}{l}\text { Personalisasi beberapa smart } \\
\text { card pada aplikasi personalisasi }\end{array}$ & $\begin{array}{l}\text { Menampilkan data personalisasi } \\
\text { sebanyak dilakukan Perso }\end{array}$ & Sesuai \\
\hline
\end{tabular}

Hasil pengujian pada tabel 4 menunjukkan bahwa aplikasi web monitoring memberikan hasil sesuai yang diharapkan karena aplikasi tersebut dapat menampilkan data, baik ketika proses personalisasi ataupun pencatatan kehadiran.

\section{KESIMPULAN}

Berdasarkan pembahasan mengenai kombinasi antara smart card dan sidik jari untuk perancangan sistem smart attendance mahasiswa dan dosen selama jam perkuliahan di Politeknik Negeri Malang, diperoleh kesimpulan bahwa penggunaan smart card dapat diandalkan karena mampu melakukan validasi data pemegang kartu sebanyak dua kali. Validasi pertama adalah kesesuaian data smart card dengan pemegang kartu yaitu dosen dan mahasiswa. Selanjutnya, validasi kedua adalah memastikan bahwa pemegang kartu benar-benar mahasiswa yang bersangkutan dengan cara scan 
sidik jari agar tidak terjadi tindakan kecurangan seperti titip absen. Dengan menggunakan kombinasi kedua teknologi tersebut, sistem smart attendance ini dapat menjadi solusi bagi permasalahan pencatatan kehadiran selama proses belajar mengajar pada perguruan tinggi atau institusi pendidikan yang lain.

Meskipun penggunaan kombinasi smart card dan sidik jari mempunyai beberapa keunggulan dibandingkan dengan teknologi lainnya, sistem smart attendance yang dirancang ini membutuhkan pengecekan template sidik jari ke database. Dengan demikian, pada penelitian selanjutnya sebaiknya dapat melakukan ekstraksi template kemudian disimpan pada smart card tetapi masih tetap terbaca pada finger scan ketika dilakukan validasi. Selain itu, pengembangan algoritma yang dapat dijalankan oleh controller untuk mencocokkan template sidik jari dapat ditambahkan ke dalam sistem sehingga waktu pemrosesan yang dibutuhkan oleh sensor sidik jari dapat dikurangi.

\section{REFERENSI}

[1] J. Chen and T. F. Lin, "Class Attendance and Exam Performance: A Randomized Experiment," J. Econ. Educ., vol. 39, no. 3, pp. 213-227, 2008.

[2] C. Dobkin, R. Gil, and J. Marion, "Skipping class in college and exam performance: Evidence from a regression discontinuity classroom experiment," Econ. Educ. Rev., vol. 29, no. 4, pp. 566-575, 2010.

[3] J. W. Westerman, L. A. Perez-Batres, B. S. Coffey, and R. W. Pouder, "The Relationship Between Undergraduate Attendance and Performance Revisited: Alignment of Student and Instructor Goals," Decis. Sci. J. Innov. Educ., vol. 9, no. 1, pp. 49-67, 2011.

[4] P. T.-M. Chou and Y.-H. Kuo, "Examining Factors Relating to Classroom Attendance and Performance," J. Stud. Educ., vol. 2, no. 2, pp. 193-204, 2012.

[5] Y. Rafita, "Analisis Faktor-Faktor yang Mempengaruhi Kecurangan Akademik (Titip Absen) pada Mahasiswa S1 Fakultas Matematika dan Ilmu Pengetahuan Alam Universitas Islam Indonesia," Khazanah, vol. 5, no. 2, pp. 25-37, 2012.

[6] N. A. Pamungkas and H. Mustafidah, "Analisis Kedisiplinan Belajar Mahasiswa dan Kehadiran Mahasiswa Terhadap Nilai Mata Kuliah Menggunakan Teori Kuantifikasi Fuzzy," SAINTEKS, vol. 13, no. 1, pp. 71-82, 2016.

[7] O. G. Chiagozie and O. G. Nwaji, "Radio Frequency Identification (RFID) Based Attendance System with Automatic Door Unit," no. April 2012, 2018.

[8] T. C. Adeniran, Y. Sanni, N. Faruk, and L. A. Olawoyin, "Design and Implementation of an Automated Attendance Monitoring System for a Nigerian University using RFID," African J. Comput. ICT, vol. 12, no. 2, pp. 72-89, 2019.

[9] A. A. A. Rahni, N. Zainal, M. F. Z. Adna, N. E. Othman, and M. F. Bukhori, "Development of the online student attendance monitoring system $\left(\mathrm{SAMS}^{\mathrm{TM}}\right)$ based on QR-codes and mobile devices," J. Eng. Sci. Technol., vol. 10, pp. 28-40, 2015.

[10] G. R. T. White, G. Gardiner, G. Prabhakar, and A. A. Razak, "A Comparison of Barcoding and RFID Technologies in Practice," J. Information, Inf. Technol. Organ. (Years 1-3), vol. 2, pp. 119-132, 2007.

[11] M. Rahardi and R. Fajarudin, "Sistem Autentikasi Presensi Mahasiswa Berbasis Radio Frequency Identification (RFID)," SISTEMASI, vol. 8, no. 2, pp. 276-281, 2019.

[12] G. M. Gaukler and R. W. Seifert, "Applications of RFID in Supply Chains," in Trends in Supply Chain Design and Management: Technologies and Methodologies, London: Springer, 2007, pp. 29-48.

[13] K. Finkenzeller, "Fundamentals and Applications in Contactless Smart Cards, Radio Frequency Identification and Near-Field Communication," in RFID Handbook, John Wiley \& Sons, 2010, pp. 1-6.

[14] R. A. J. Gining, S. S. M. Fauzi, I. M. Ayub, M. N. F. Jamaluddin, I. Puspitasari, and Okfalisa, "Design and development of activity attendance monitoring system based on RFID," Indones. J. Electr. Eng. Comput. Sci., vol. 17, no. 1, pp. 500-507, 2020.

[15] A. I. Florea, "Benefits and Drawbacks in Using the RFID (Radio Frequency Identification) System in Supply Chain Management," in Modelling, Computation and Optimization in Information Systems and Management Sciences, vol. 360, Cham: Springer, 2015, pp. 177-188. 
[16] A. K. Jain, A. Ross, and S. Prabhakar, "An Introduction to Biometric Recognition," IEEE Trans. Circuits Syst. Video Technol., vol. 14, no. 1, pp. 4-20, 2004.

[17] J. Joseph and K. P. Zacharia, "Automatic Attendance Management System Using Face Detection," Int. J. Sci. Res., vol. 2, no. 11, pp. 327-330, 2013.

[18] P. Wagh, R. Thakare, J. Chaudhari, and S. Patil, "Attendance System based on Face Recognition using Eigen face and PCA Algorithms," in 2015 International Conference on Green Computing and Internet of Things (ICGCIoT), 2016, pp. 303-308.

[19] A. Y. Ananta et al., "Smart monitoring system for teaching and learning process at the university," in IOP Conference Series: Materials Science and Engineering, 2020, vol. 732, no. 1.

[20] C. B. Chew, M. Mahinderjit-Singh, K. C. Wei, T. W. Sheng, M. H. Husin, and N. H. A. H. Malim, "Sensors-enabled Smart Attendance Systems Using NFC and RFID Technologies," Int. J. New Comput. Archit. their Appl., vol. 5, no. 1, pp. 19-28, 2015.

[21] P. K. Singh, N. Kumar, and B. K. Gupta, "Smart Card ID: An Evolving and Viable Technology," Int. J. Adv. Comput. Sci. Appl., vol. 9, no. 3, pp. 115-124, 2018.

[22] J. Y. Park, D. Kim, and Y. Lim, "Use of Smart Card Data to Define Public Transit Use in Seoul, South Korea," Transp. Res. Rec. J. Transp. Res. Board, vol. 2063, no. 1, pp. 3-9, 2008.

[23] S. A. M. Rizvi, H. S. Rizvi, and Z. Al-baghdadi, "Smart Cards: The Future Gate," in Proceedings of the World Congress on Engineering and Computer Science, 2010, vol. I.

[24] S. Thangaraju, "Near Field Communication in Medical Devices," White Pap., pp. 1-14, 2013. 